\title{
Electrodeposition of Co-rich Cu-Co Alloys from Sodium Tartrate Baths Using Direct (DC) and Single Pulsed Current (SPC)
}

\author{
Thaís Machado de Souza ${ }^{a}$, Dalva Cristina Baptista do Lago $^{a} \mathbb{D}^{,}$, Lilian Ferreira de Senna $*^{\mathbb{D}}$ \\ ${ }^{a}$ Laboratório de Corrosão e Eletroquímica - LEC, Instituto de Química, Universidade do Estado do \\ Rio de Janeiro - UERJ, Rua São Francisco Xavier, 524, Pavilhão Haroldo Lisboa da Cunha, Sala 427, \\ Maracanã, 20550-013, Rio de Janeiro, RJ, Brasil
}

Received: April 13, 2018; Revised: December 01, 2018; Accepted: March 31, 2019

\begin{abstract}
$\mathrm{Cu}-\mathrm{Co}$ alloys were electrodeposited on steel substrates from alkaline sodium tartrate electrolyte using direct and single pulsed current (DC and SPC, respectively). The electrodeposition bath was composed by $0.02 \mathrm{~mol} \mathrm{~L}^{-1}$ of $\mathrm{CuSO}_{4} .5 \mathrm{H}_{2} \mathrm{O}, 0.10 \mathrm{~mol} \mathrm{~L}^{-1}$ of $\mathrm{CoSO}_{4} .7 \mathrm{H}_{2} \mathrm{O}$ and $0.50 \mathrm{~mol} \mathrm{~L}^{-1}$ of $\mathrm{Na}_{2} \mathrm{C}_{4} \mathrm{H}_{4} \mathrm{O}_{6} .4 \mathrm{H}_{2} \mathrm{O}$. Using both kind of deposition processes, it was verified that the applied current density $(\mathrm{j})$ affected the cathodic current efficiency $\left(\mathrm{E}_{\mathrm{f}}\right)$, the copper and cobalt contents in the coatings (wt. \% $\mathrm{Cu}$ and wt. $\% \mathrm{Co}$, respectively), the morphology and the anticorrosive performance of the coatings (based on the transfer charge resistance, $\left(R_{c t}\right)$ values). Comparing the results obtained for DC and SPC coatings, those produced by single pulsed current improved the $\mathrm{E}_{\mathrm{f}}$ values and decreased the grain sizes. Concerning the conditions used in this work, the coating produced under the conditions of Experiment 4', using $\mathrm{j}_{\mathrm{m}}=40 \mathrm{~A} \mathrm{~m}^{-2}$ and SPC mode, presented $15.9 \mathrm{wt} \%$ Co, the most compact morphology, the smallest grain size and the highest $\mathrm{R}_{\mathrm{ct}}$ value after $24 \mathrm{~h}$ of exposure in the saline medium.
\end{abstract}

Keywords: Electrodeposition, $\mathrm{Cu}$-Co alloys, sodium tartrate baths, anticorrosive coatings.

\section{Introduction}

$\mathrm{Cu}-\mathrm{Co}$ alloy coatings can be deposited on a substrate surface to produce functional coating/substrate systems presenting enhanced properties. These coatings present several interesting applications, depending on the cobalt content in the alloy and on the substrate used. For example, low cobalt $\mathrm{Cu}-\mathrm{Co}$ alloys present giant magneto resistance properties. When deposited on silicon, copper or platinum substrates, these alloys can be used in sensor technology and data storage systems ${ }^{1-5}$. On the other hand, $\mathrm{Cu}-\mathrm{Co}$ alloy coatings with high cobalt content and produced on other substrates can also find suitable applications, mainly for catalytic purposes ${ }^{4,6-8}$ and for anticorrosive coatings ${ }^{7-15}$.

The production of these coatings by electrodeposition can be an interesting alternative to decrease the deposition process costs. As the difference between the reduction potentials of $\mathrm{Cu}$ (II) and Co (II) ions is about $-0.60 \mathrm{~V}$, however, the simultaneous reduction of both cations on the cathode can only be achieve by using a complexing agent ${ }^{5,12-14}$. Despite its toxicity, cyanide has been, for a long time, the most used ligand in the electrodeposition of copper alloys ${ }^{8,14-16}$. In order to minimize this problem, environmentally friendly compounds can be used as alternative complexing agents to produce alloy coatings ${ }^{7,14-20}$. The use of less toxic electrolytes may also decrease the costs of the electroplating industries, which are directly related to the treatment of effluents and to the use of reinforced exhaust equipments.

*e-mail: 1senna@uerj.br
In this context, tartrate ion may be used as an alternative complexing agent for the electrodeposition of alloy coatings. Tartrate is the anion of a dicarboxylic acid and can originate stable complexes with both $\mathrm{Cu}$ (II) and other M (II) ions ${ }^{21-24}$. In fact, ammonium tartrate has been used to produce stable alkaline baths for the Fe-Co-Pt alloy deposition ${ }^{25}$, while a mixed bath composed of sodium tartrate and sodium citrate has enhanced the quality of the $\mathrm{Cu}-\mathrm{Ni}$ alloy coatings produced by electrodeposition in platinum substrate ${ }^{26}$. Tartrate has also been studied as a levelling additive for the electrodeposition of $\mathrm{Cu}-\mathrm{Sn}$ alloy ${ }^{27}$, influencing the layer morphology and decreasing the energy consumption during the electrodeposition process.

$\mathrm{Cu}$-Co alloy coatings can be deposited by using direct current (DC) or pulsed current (PC). Each process affects the mass transport, current distribution and the electrical double layer differently, producing coatings with diverse composition, surface roughness and morphology ${ }^{24-34}$. Although the less cost and more simplicity of the DC, several studies show that the use of pulsed current presents some advantages in the alloy electrodeposition, enhancing the adhesion, density, resistivity and ductility of the coatings. In addition, layers presenting lower porosity, morphological uniformity and more refined grains can also be achieved $5,7,13,20,35-38$.

Earlier, anticorrosive $\mathrm{Co}$-rich $\mathrm{Cu}-\mathrm{Co}$ coatings were produced on carbon steel substrate from both citrate and glycinate baths and using DC process ${ }^{14,15}$. In the present work, Co-rich $\mathrm{Cu}-\mathrm{Co}$ alloys coating were electrodeposited on the same substrate, from a bath containing sodium tartrate as the complexing agent. Our goal is to evaluate the effects of the applied current density, using both DC and PC processes, 
on the cathodic current efficiency $\left(\mathrm{E}_{\mathrm{f}}\right)$, the metal contents in the coatings (wt.\% $\mathrm{Cu}$ and wt.\% $\mathrm{Co}$ ), the morphology and microstructure of the coatings, as well as to produce coating/ substrate systems with high anticorrosive performance.

\section{Experimental Procedures}

\subsection{Spectrophotometric experiments}

Spectrophotometric visible absorption spectra of solutions containing $0.02 \mathrm{~mol} \mathrm{~L}^{-1}$ of $\mathrm{CuSO}_{4} \cdot 5 \mathrm{H}_{2} \mathrm{O}$ and $0.10 \mathrm{~mol} \mathrm{~L}^{-1}$ of $\mathrm{CoSO}_{4} .7 \mathrm{H}_{2} \mathrm{O}$, with and without $0.50 \mathrm{~mol} \mathrm{~L}^{-1}$ of sodium tartrate $\left(\mathrm{Na}_{2} \mathrm{C}_{4} \mathrm{H}_{4} \mathrm{O}_{6} \cdot 4 \mathrm{H}_{2} \mathrm{O}\right)$, from now on denominated Solutions 1 and 2, respectively were performed using a M501 Single Beam CAMSPEC UV/VIS spectrophotometer. The spectra were recorded at $25^{\circ} \mathrm{C}$, from 900 to $400 \mathrm{~nm}$. The $\mathrm{pH}$ of Solution 1 was around 4.5, while the $\mathrm{pH}$ of Solution 2 was adjusted to 8.3 by using $\mathrm{NaOH} 4.0 \mathrm{~mol} \mathrm{~L}^{-1}$. All the reagents used to prepare these solutions were achieved from Sigma Aldrich (>99\%).

\subsection{Cyclic voltammetry experiments}

Cyclic voltammetry experiments were carried out using the same solutions described in Section 2.1 of this work, at the same $\mathrm{pH}$ values. A three-electrode cell composed of a graphite disk (exposed area $=0.28 \mathrm{~cm}^{2}$ ) as the working electrode, a platinum wire as the counter electrode, and saturated mercurous sulfate (SSE) as the reference electrode was used for the cyclic voltammetry experiments. The voltammograms were performed using a potenciostat/galvanostat Autolab PGSTAT $302 \mathrm{~N}$ with a scan rate of $10 \mathrm{mV} \mathrm{s}^{-1}$. The potential scan varied between $1.0 \mathrm{~V}_{\mathrm{SSE}}$ to $-1.7 \mathrm{~V}_{\mathrm{SSE}}$ and then was reversed. The experiments were carried out without stirring, at $25^{\circ} \mathrm{C}$ and in naturally aerated solution. Before each experiment, the graphite electrode was polished with a 600 grit sandpaper. Then, it was washed with distilled water and ethanol and finally dried.

\subsection{Cathodic polarization curves}

Cathodic polarization curves of the AISI 1020 steel substrate were galvanostatically obtained using only Solution $2\left(0.02 \mathrm{~mol} \mathrm{~L}^{-1}\right.$ of $\mathrm{CuSO}_{4} .5 \mathrm{H}_{2} \mathrm{O}, 0.10 \mathrm{~mol} \mathrm{~L}^{-1}$ of $\mathrm{CoSO}_{4} .7 \mathrm{H}_{2} \mathrm{O}$ and $0.50 \mathrm{~mol} \mathrm{~L}^{-1}$ of sodium tartrate), at the same $\mathrm{pH}$ value used in Sections 2.1 and 2.2.

The experiments were performed in a three-electrode cell, at $25^{\circ} \mathrm{C}$, with a stirring speed of $300 \mathrm{rpm}$. In this cell, the working electrodes were carbon steel disks (exposed area $\left.=4.90 \times 10^{-4} \mathrm{~m}^{2}\right)$, which were first polished with emery paper (100 to $600 \mathrm{mesh}$ ) and degreased in an alkaline sodium lauril sulfate $0.5 \mathrm{~g} \mathrm{~L}^{-1}$ solution at $80{ }^{\circ} \mathrm{C}$ for 10 minutes. Then, the disks were washed with deionized water and alcohol, and finally dried with warm air before immersion in the electrodeposition solution. A platinum spiral, used as the counter electrode, was immersed in $20 \% \mathrm{v} / \mathrm{v} \mathrm{HNO}_{3}$ solution for 1 minute, immediately before being used in the experiments, to remove any oxide layer that could be present. Finally, the reference electrode was the saturated mercury (I) sulfate electrode $\left(\mathrm{Hg} / \mathrm{Hg}_{2} \mathrm{SO}_{4}, \mathrm{SSE}\right)$.

The applied potential ranged from the open circuit potential until $-2,0 \mathrm{~V}_{\mathrm{SSE}}$, using a scanning rate of $1 \mathrm{mV} \mathrm{s}^{-1}$ and the same potentiostat/galvanostat Autolab PGSTAT $302 \mathrm{~N}$ used in Section 2.2.

\subsection{Alloy electrodeposition}

$\mathrm{Cu}-\mathrm{Co}$ alloy coatings were electrodeposited using the same electrolytic cell, electrodeposition bath and equipment described in Section 2.3. The electrodeposition experiments were carried out in duplicate series, using direct current (DC) or simple pulsed current (SPC). In the present work, the chosen current density values (j) used in DC deposition were the same selected as the average current density $\left(\mathrm{j}_{\mathrm{m}}\right)$ in SPC deposition. The deposition conditions for DC and SPC deposition are shown in Table 1.

Each electrodeposition time was calculated, based on the Faraday's law ${ }^{10}$, to produce a $5 \mathrm{mg}$ coating (theoretical mass value). The coatings were dissolved in $20 \% \mathrm{v} / \mathrm{v} \mathrm{HNO}_{3}$, and the alloy composition was determined by flame atomic absorption spectrometry (FAAS), applying the conditions recommended by the instrument operation manual (AAnalyst 300, Perkin-Elmer). The metallic coating mass $\left(\mathrm{m}_{\text {deposited }}\right)$ was also obtained from this analysis. These results and the theoretical mass were used to calculate the cathodic current efficiency, $\mathrm{E}_{\mathrm{f}}$, for each deposition time $\mathrm{e}^{15,38,39}$.

The content of each metal in the coatings was calculated as the wt. \% Cu and wt. \% Co, using Equations 1 and 211,14,15,17, respectively.

$$
\begin{aligned}
& w t \% C u=\frac{m_{C u}}{m_{\text {deposited }}} \times 100 \% \\
& w t \% C o=\frac{m_{C o}}{m_{\text {deposited }}} \times 100 \%
\end{aligned}
$$

The thickness of the coatings $(h)$ was calculated from Equation $3^{15}$ :

$$
h=\frac{Q M_{c}}{A \rho_{c} n F}
$$

\begin{tabular}{|c|c|c|c|c|}
\hline \multicolumn{2}{|c|}{ DC } & \multicolumn{3}{|c|}{ SPC* } \\
\hline Exp. no & $\mathbf{j}\left(\mathrm{A} \mathrm{m}^{-2}\right)$ & Exp. no & $\mathbf{j}_{\mathrm{m}}\left(\mathrm{A} \mathrm{m}^{-2}\right)$ & $\mathbf{j}_{\mathrm{c}}\left(\mathrm{A} \mathrm{m}^{-2}\right)$ \\
\hline 1 & 1.5 & 1 ' & 1.5 & 5.0 \\
\hline 2 & 5.0 & $2^{\prime}$ & 5.0 & 16.7 \\
\hline 3 & 15.0 & $3^{\prime}$ & 15.0 & 50.0 \\
\hline 4 & 40.0 & $4^{\prime}$ & 40.0 & 133.3 \\
\hline
\end{tabular}

Table 1. Conditions used to produce the electrodeposited $\mathrm{Cu}-\mathrm{Co}$ coatings using DC and SPC modes. 
where $M_{\mathrm{c}}$ and $\rho_{\mathrm{c}}$ are, respectively, the molar mass $\left(\mathrm{g} \mathrm{mol}^{-1}\right)$ and the density of the coating $\left(\mathrm{g} \mathrm{cm}^{-3}\right)$, considering the contents of $\mathrm{Cu}$ and $\mathrm{Co}$ in each deposited coating; $A$ is the electrode area $\left(4.9 \mathrm{~cm}^{2}\right) ; n$ is the number of electrons in the reaction (in the present case, $n=2$ ); and $F$ is the Faraday constant $(\sim 96500 \mathrm{C}) . Q$ is the charge used $\left(\mathrm{C} \mathrm{mol}^{-1}\right)$, calculated from Equation $4^{15}$, also considering the mass deposited in each experiment:

$$
Q=\frac{m_{\text {deposited }} n F}{M_{c}}
$$

Based on earlier experiments ${ }^{38}$, a pulse frequency $(\mathrm{F})$ of $1000 \mathrm{~Hz}$ and a duty cycle $(\gamma)$ of $30 \%$ were the parameters chosen to be used in the SPC experiments. The cathodic current densities $\left(\mathrm{j}_{\mathrm{c}}\right)$ were calculated using Equation $5^{28,29,40}$, whereas the current-on time and the current-off time $\left(\mathrm{t}_{\mathrm{on}}\right.$ and $\mathrm{t}_{\text {off }}$, respectively) were obtained from Equation $6^{28,29,40}$. All of these parameters are also shown in Table 1. Because simple PC experiments were used in this study, the anodic current density $\left(\mathrm{j}_{\mathrm{a}}\right)$ was always equal to zero and is not shown in Equation 5.

$$
\begin{gathered}
j_{m}=\frac{j_{c} \times t_{o n}}{\left(t_{o n}+t_{o f f}\right)} \\
\gamma=\frac{t_{o n}}{\left(t_{o n}+t_{o f f}\right)} \times 100 \%
\end{gathered}
$$

\subsection{Coating characterization}

Based on the chemical composition of the $\mathrm{Cu}-\mathrm{Co}$ alloy coatings produced in Section 2.2, those presenting high Co content were selected to be microstructural, morphological and electrochemically characterized.

\subsubsection{Microstructure characterization}

X-rays diffractograms (XRD) of the selected coatings were obtained using a diffractometer (Rigaku Miniflex II) with a copper source $(\mathrm{CuK}=1.5406 \AA)$, at $40 \mathrm{kV}$. The $2 \theta$ ranged from $10^{\circ}$ to $90^{\circ}$, at a scanning rate of $0.050^{\circ} \mathrm{s}^{-1}$. The more prominent diffractogram lines from the $\mathrm{Cu}$-Co alloy deposit

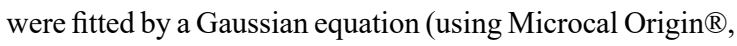
release 8.0 ) to obtain their $2 \theta$ values, which were used to calculate the $d(\mathrm{~h} \mathrm{k} \mathrm{l})$ parameters of the diffraction lines.

\subsubsection{Morphological characterization}

Scanning electron microscopy (SEM) was performed using a JEOL JSMG510LV microscope to evaluate the surface morphology of the selected coatings. The samples were cleaned with alcohol, dried with warm air and adapted to the stub with a conductive tape. The analysis was carried out in high vacuum, using secondary electron mode, with magnification of $10.000 \mathrm{X}$.

\subsubsection{Electrochemical characterization}

Electrochemical impedance spectroscopy (EIS) experiments of the selected coating/substrate systems and the bare steel substrate were performed in a $0.5 \mathrm{~mol} \mathrm{~L}^{-1} \mathrm{NaCl}$ solution $(\mathrm{pH}=7.06)$, by employing the same potentiostat/ galvanostat Autolab PGSTAT 302N earlier mentioned. In the electrochemical cell used for both experiments, the working electrodes were the coating/substrate systems produced under the conditions described in Table 1, or the steel substrate, the counter electrode was a platinum spiral, while the reference electrode was a saturated calomel electrode (SCE).

All of the electrochemical assays were performed at $25^{\circ} \mathrm{C}$ and without stirring, after stabilization of the system in its open circuit potential (OCP) for $1 \mathrm{~h}$. The EIS experiments were carried out at the $\mathrm{OCP}$ values, using a frequency range of $10^{5}$ to $10^{-3} \mathrm{~Hz}$ and amplitude of $10 \mathrm{mV}$. The EIS data were simulated by equivalent electrical circuits, using the software NOVA 1.10 (Metrohm Autolab). The value of the electric double layer capacitance $\left(\mathrm{C}_{\mathrm{DL}}\right)$ was calculated based on the constant phase element (CPE), by using Equation $7^{41}$.

$$
C_{D L}=(C P E)^{\frac{1}{N}} \times R_{c t}^{\left(\frac{1}{N}-1\right)}
$$

where $\mathrm{R}_{\mathrm{ct}}$ is the charge transfer resistance of the film.

\subsubsection{Stability of the coatings}

The stability of the selected Co-rich $\mathrm{Cu}-\mathrm{Co}$ coatings presenting the best anticorrosive performances was evaluated using EIS at the corrosion potential, with $10 \mathrm{mV}$ amplitude and a frequency range from $100 \mathrm{kHz}$ to $1 \mathrm{mHz}$. The EIS spectra were recorded at $25^{\circ} \mathrm{C}$, after $24 \mathrm{~h}$ of immersion in the same $\mathrm{NaCl}$ solution previously mentioned in Section 2.3.3. The selected coating/substrate systems, platinum net and saturated calomel electrode (SCE) were used as the working electrode, counter electrode and reference electrode, respectively. The same potentiostat/galvanostat used in Section 2.5.3 (Autolab PGSTAT 302N) was used to perform these experiments.

\section{Results and Discussion}

\subsection{Spectrophotometric experiments}

Figure 1 shows the electronic spectra in the visible range obtained using Solutions 1 and 2 (Section 2.1), in order to verify the influence of tartrate ion on the electronic densities of the aqueous metallic ions $\mathrm{Cu}$ (II) and $\mathrm{Co}$ (II). By comparing both spectra, a displacement of the absorption maxima related to $\mathrm{Cu}$ (II) ion from $810 \mathrm{~nm}$ to $735 \mathrm{~nm}$ can be observed in the spectrum recorded using the solution containing tartrate (B). It means that tartrate acts as a complex agent by forming bonds with $\mathrm{Cu}$ (II) ions that are stronger than those formed 


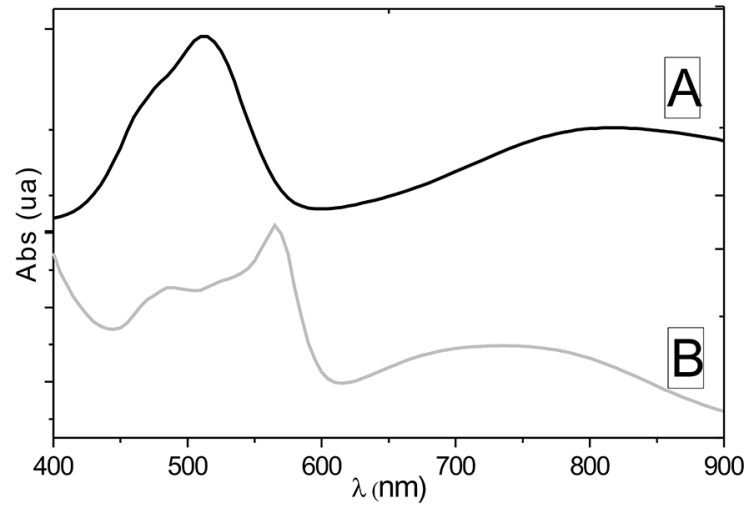

Figure 1. Electronic spectra of (A) Solution $1-0.02 \mathrm{~mol} \mathrm{~L}^{-1}$ $\mathrm{CuSO} 4.5 \mathrm{H} 2 \mathrm{O}$ and $0,10 \mathrm{~mol} \mathrm{~L}^{-1} \mathrm{CoSO}_{4} .7 \mathrm{H}_{2} \mathrm{O}$ and (B) Solution 2 - $0.02 \mathrm{~mol} \mathrm{~L}^{-1} \mathrm{CuSO}_{4} \cdot 5 \mathrm{H}_{2} \mathrm{O}, 0,10 \mathrm{~mol} \mathrm{~L}^{-1} \mathrm{CoSO}_{4} \cdot 7 \mathrm{H}_{2} \mathrm{O}$ and $0.50 \mathrm{~mol} \mathrm{~L}^{-1}$ sodium tartrate $\mathrm{Na}_{2} \mathrm{C}_{4} \mathrm{H}_{4} \mathrm{O}_{6} \cdot 4 \mathrm{H}_{2} \mathrm{O}$

with water ${ }^{42}$. Therefore, stable $\mathrm{Cu}(\mathrm{II})$-tartrate complexes were formed, under the present condition.

On the other hand, a displacement of the absorption maxima related $\mathrm{Co}$ (II) ion was verified from $510 \mathrm{~nm}$ to $565 \mathrm{~nm}$, when compared the curves obtained for Solutions 1 (A) and 2 (B). In agreement, this result suggests that the tartrate ion forms bonds with the $\mathrm{Co}$ (II) ions that are weaker than those formed with water, suggesting that a less stable $\mathrm{Co}$ (II)-tartrate complex should have been formed under the conditions of this work. These results are interesting, as the presence of a more stable $\mathrm{Cu}$ (II)-tartrate complex should decrease the activity of the most noble metal ion in solution, the $\mathrm{Cu}$ (II) ion.

\subsection{Cyclic voltammetry experiments}

The cyclic voltammograms of the graphite obtained in Solutions 1 and 2 are presented in Figure 2A, while the amplification of these curves is shown in Figure 2B. The voltammetric results obtained from the $\mathrm{Cu}-\mathrm{Co}$ and $\mathrm{Cu}-\mathrm{Co}-$ Tartrate curves (Solutions 1 and 2, respectively), are shown in Table 2. During the negative scan, the starting deposition potential, $\mathrm{E}_{\mathrm{sd}}$, was considered as the potential at which a significant variation in the cathodic current density was noted. The cathodic and anodic peak potentials $\left(\mathrm{E}_{\mathrm{cp}}\right.$ and $\mathrm{E}_{\text {ap }}$, respectively) for each bath are also shown in this table.

The results obtained using Solution 1 show a cathodic peak (C1), related to the reduction of $\mathrm{Cu}$ (II) ions and a sharp cathodic peak (C2), which is associated to the reduction of Co (II) ions, at very high negative potentials. It is also possible to note the nucleation loop, which is a usually observed behavior for the reduction processes of Co (II) ions in aqueous media ${ }^{43}$. In the anodic scan, three well-defined peaks are verified: A2, which refers to the oxidation of Co (0) to Co (II) ions, A1, which is related to the oxidation of $\mathrm{Cu}(0)$ to $\mathrm{Cu}$ (II) ions and $\mathrm{A} 3$, which is associated to the oxidation of Co (II) to Co (III) species $^{24}$.
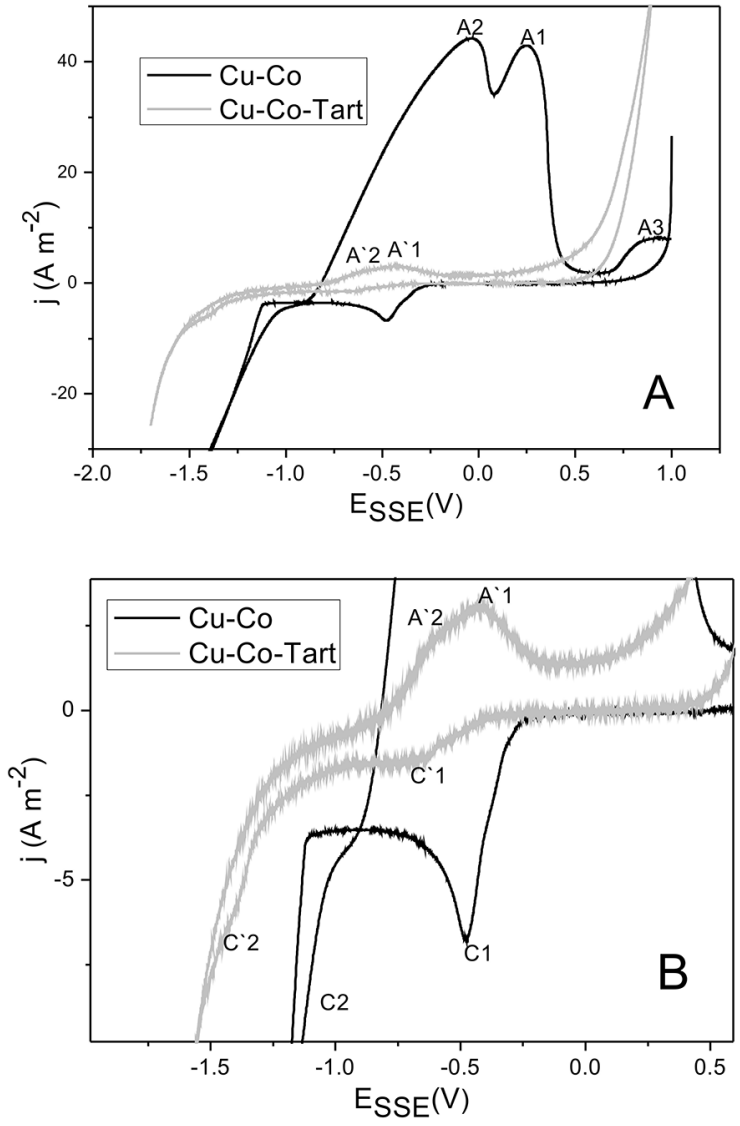

Figure 2. (A) Cyclic voltammograms of graphite electrode in Solutions 1 and 2; (B) Magnification of (A).

A strong decrease is verified in the current density values obtained during the cyclic voltammogram of the graphite in Solution 2. Therefore, this process is observed more clearly in Figure 2B. The cathodic reduction process of $\mathrm{Cu}$ (II) ions from a tartrate bath (Solution 2) starts at more negative potentials, when compared to the results obtained using Solution 1. The cathodic peak related to this process $\left(C^{\prime} 1\right)$ is also shifted to more negative potential values (Table 2). These results corroborate those shown in Figure 1 and indicate the influence of the coordinated ligand on the metallic center, causing an increase of the overvoltage of the electrode for the reduction of $\mathrm{Cu}$ (II) ions. Table 2 and Figure 2 also show that the reduction process of Co (II) ions from a tartrate-containing solution (Solution 2) starts at more positive potentials than that verified for Solution 1. The cathodic peak related to this process (C'2) is also shifted to more positive potential values, when compared to that verified for Solution $1(\mathrm{C} 2)$. These results also agree to the spectrophotometric ones (Figure 1), indicating that the reduction of Co (II) ions from Solution 2 is favored.

Liu and Wang ${ }^{44}$ have shown, using cyclic voltammetry and electrochemical impedance spectroscopy experiments, that the reduction of $\mathrm{Cu}(\mathrm{II})$-citrate and $\mathrm{Co}(\mathrm{II})$-citrate was 
Table 2. Voltammetric results obtained from the experiments on graphite electrode in Solutions $1\left(0.02 \mathrm{~mol} \mathrm{~L}^{-1} \mathrm{Cu}\right.$ (II), $0.10 \mathrm{~mol} \mathrm{~L}^{-1} \mathrm{Co}$ (II)) and 2 (0.02 $\mathrm{mol} \mathrm{L}^{-1} \mathrm{Cu}(\mathrm{II}), 0.10 \mathrm{~mol} \mathrm{~L}^{-1} \mathrm{Co}(\mathrm{II}), 0.5 \mathrm{~mol} \mathrm{~L}^{-1}$ tartrate).

\begin{tabular}{|c|c|c|c|c|}
\hline \multirow{2}{*}{$\begin{array}{l}\text { Solution } \\
\text { VR * }\end{array}$} & \multicolumn{2}{|c|}{1} & \multicolumn{2}{|c|}{2} \\
\hline & $\mathrm{Cu}$ & Co & $\mathrm{Cu}$ & $\mathrm{Co}$ \\
\hline$E_{\text {sd }}(V$ vs SSE $)$ & -0.277 & -1.117 & -0.405 & -0.932 \\
\hline$E_{\text {cp }}(\mathrm{V} v \mathrm{SSSE})$ & $-0.484(\mathrm{C} 1)$ & $-1.461(\mathrm{C} 2)$ & $-0.639\left(C^{\prime} 1\right)$ & $-1.394\left(C^{\prime} 2\right)$ \\
\hline \multirow{2}{*}{$E_{\text {ap }}($ V vs SSE $)$} & $0.246(\mathrm{~A} 1)$ & $0.874(\mathrm{~A} 3)$ & $-0.420\left(\mathrm{~A}^{`} 1\right)$ & $-0.614\left(\mathrm{~A}^{`} 2\right)$ \\
\hline & $-0.038(\mathrm{~A} 2)$ & & & \\
\hline
\end{tabular}

*Voltammetric results: $\mathrm{E}_{\mathrm{sd}}$ — starting deposition potential; $\mathrm{E}_{\mathrm{cp}}$ — cathodic peak potential; $\mathrm{E}_{\mathrm{ap}}$ — anodic peak potential.

divided into two steps: first, the metallic ions in $\mathrm{Cu}$ (II)-citrate and $\mathrm{Co}$ (II)-citrate complexes are reduced to an intermediate state and then, to metallic $\mathrm{Cu}$ and $\mathrm{Co}$. Although tartrate is an anion from a carboxylic acid very similar to citric acid, this intermediate state could not be verified in the voltammetric experiments presented in this work (Figure 2B). Therefore, based on the present results, it is only possible to propose that the reduction of $\mathrm{Cu}$ (II) and $\mathrm{Co}$ (II) ions from a solution containing sodium tartrate is dependent on the stability of their respective complexes, as the $\mathrm{Cu}$-Co alloy deposition from a tartrate bath may include a chemical step involving the dissociation of these metallic complexes.

In the anodic scan, the anodic peaks related to the Co and $\mathrm{Cu}$ oxidation (A'2 and A'1, respectively) are closer than those observed for the Solution 1, which may suggest that, under these conditions, $\mathrm{Cu}-\mathrm{Co}$ alloy was produced during the negative voltammetric scan.

\subsection{Cathodic polarization curves}

Figure 3 presents the cathodic polarization curve of the steel substrate in the solution containing $0.02 \mathrm{~mol} \mathrm{~L}^{-1}$ $\mathrm{CuSO}_{4} .5 \mathrm{H}_{2} \mathrm{O}, 0,10 \mathrm{~mol} \mathrm{~L}^{-1} \mathrm{CoSO}_{4} .7 \mathrm{H}_{2} \mathrm{O}$ and $0.50 \mathrm{~mol} \mathrm{~L}^{-1}$ sodium tartrate $\mathrm{Na}_{2} \mathrm{C}_{4} \mathrm{H}_{4} \mathrm{O}_{6} \cdot 4 \mathrm{H}_{2} \mathrm{O}$. This curve presents a typical profile of steel in an electrolytic bath for copperalloy coating produced ${ }^{8,11,14,15,39}$. It is possible to note a less negative linear region (from the OCP until approximately $-1.0 \mathrm{~V}_{\mathrm{SSE}}$ ), related to copper deposition from charge transfer processes. A strong decrease is then observed in the potential (until approximately $-1.4 \mathrm{~V}_{\mathrm{SSE}}$ ), corresponding to the copper deposition from mass transfer processes; and another linear range, at more negative potentials, generally related to the reduction processes of the less noble metallic ion.

This experiment was used to select the values of $\mathrm{j}$ to be used in the electrodeposition of the alloy, using both DC and SPC. Based on the polarization curve and on our earlier results ${ }^{5,8,14,15}$, four values of current density $\left(1.5 \mathrm{~A} \mathrm{~m}^{-2}\right.$, $5 \mathrm{~A} \mathrm{~m}^{-2}, 15 \mathrm{~A} \mathrm{~m}^{-2}$ and $40 \mathrm{~A} \mathrm{~m}^{-2}$ ) were selected to produce the $\mathrm{Cu}$-Co coatings on the steel substrates. As mentioned in Section 2.3, the same values were used as $\mathrm{j}_{\mathrm{m}}$ in the SPC experiments. These values are presented in Figure 3 as the number of the experiments shown in Table 1. As the main goal of this work was to produce cobalt-rich $\mathrm{Cu}$-Co coatings, high $\mathrm{j}$ values were chosen preferably.

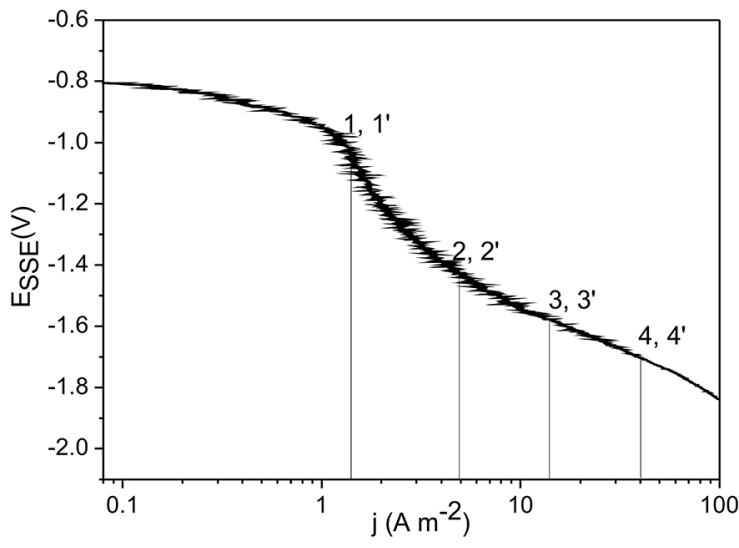

Figure 3. Cathodic polarization curves of the steel substrate in the electrolytic bath composed by $0.02 \mathrm{~mol} \mathrm{~L}^{-1} \mathrm{CuSO}_{4} \cdot 5 \mathrm{H}_{2} \mathrm{O}, 0.10 \mathrm{~mol} \mathrm{~L}^{-1}$ $\mathrm{CoSO}_{4} .7 \mathrm{H}_{2} \mathrm{O}$ and $0.50 \mathrm{~mol} \mathrm{~L}^{-1}$ sodium tartrate $\mathrm{Na}_{2} \mathrm{C}_{4} \mathrm{H} 4 \mathrm{O} 6.4 \mathrm{H} 2 \mathrm{O}$. $1 / 1^{\prime}, 2 / 2$ ', $3 / 3$ ' and $4 / 4$ ' refer to the electrodeposition experiment related to the current density values chosen using this curve

\subsection{Electrodeposition experiments}

It is important to mention that the presence of a ligand in the electrodeposition bath may interfere on the alloy deposition process, mainly if one of the ions in the solution forms a more stable complex than the other ion. This effect was clearly noted in Figure 2 and Table 2. The tartrate anion is a bi-dentate ligand that can form chelates with $\mathrm{Cu}$ (II) and Co (II) ions in alkaline medium ${ }^{21-24,45}$. Depending on the tartrate concentration and on the $\mathrm{pH}$ of the solution, several $\mathrm{Cu}$ (II) and Co (II) complexes can be produced ${ }^{23,45}$, which can affect the kinetics of the electron transfer, as well as the mass transfer process, during the electrodeposition using both DC and SPC. As the stabilization constants $\left(\mathrm{K}_{\mathrm{f}}\right)$ for the $\mathrm{Cu}$-tartrate complexes are higher than those found for the Co-tartrate complexes ${ }^{23,46}$, as also suggested in Figure 1, it is expected that this bath may enhance the cobalt deposition in the coating.

The Cu-Co coatings were electrodeposited on the steel substrate by DC and SPC modes, using the tartrate bath (Solution 2) and the $\mathrm{j}\left(\right.$ or $\mathrm{j}_{\mathrm{m}}$ ) values selected in Section 3.3 and shown in Table 1. All the coatings were adherent to the substrate and their colors varied from light pink to dark gray, depending on the applied current value and on the current mode used. Table 3 presents the average current efficiency 
values $\left(\mathrm{E}_{\mathrm{f}}\right)$ for the $\mathrm{DC}$ and $\mathrm{SPC}$ electrodeposited coatings. The $\mathrm{E}_{\mathrm{f}}$ values ranged from 39 to $65 \%$ and from 46 to $78 \%$, for the DC and SPC processes, respectively. In both cases, the maximum and minimum $\mathrm{E}_{\mathrm{f}}$ value were obtained, respectively, for $\mathrm{j}=\mathrm{j}_{\mathrm{m}}=5 \mathrm{~A} \mathrm{~m}^{-2}$ and $\mathrm{j}=\mathrm{j}_{\mathrm{m}}=40 \mathrm{~A} \mathrm{~m}^{-2}$.

As $E_{f}$ is related to the amount of deposited metals in the coating, these results indicate that the metallic coating mass decreased as $\mathrm{j}$ ( or $\mathrm{j}_{\mathrm{m}}$ ) increased, suggesting that other parallel reactions could have occurred, competing with the main reactions (the metallic ions reduction). During DC electrodeposition, the transport of $\mathrm{Cu}$ (II) and $\mathrm{Co}$ (II) ions to the substrate surface will be controlled by the continuously consumption of these ions. Then, cathodic polarization occurs, which leads to the enhancement of the reactions presented in Equations 8 and 9, depending on the electrolyte $\mathrm{pH}$.

$$
\begin{aligned}
& \mathrm{H}_{2} \mathrm{O}+e^{-} \rightarrow \frac{1}{2} \mathrm{H}_{2}+\mathrm{OH}^{-} \\
& \mathrm{O}_{2}+4 \mathrm{H}^{+}+4 e^{-} \rightarrow 2 \mathrm{H}_{2} \mathrm{O}
\end{aligned}
$$

Therefore, the most probable parallel reactions under the present study conditions are the hydrogen evolution reaction (HER, Equation 8) and the oxygen reduction reaction (ORR, Equation 9), which may have consumed part of the applied $\mathrm{j}$, causing the low $\mathrm{E}_{\mathrm{f}}$ values observed in Table 3 .

Despite of this, it is possible to note that the use of SPC to deposit these coatings increased the $\mathrm{E}_{\mathrm{f}}$ values, when compared to the values obtained using DC process. This was an expected result considering that, in electrodeposition processes a negatively charged layer is formed around the cathode as the process continues. When DC is used, this layer is charged to a defined thickness and hinders the further arrival of ions from the bulk solution to the electrode surface. As the applied current is periodically turned off in the SPC mode, this layer can discharge somewhat and the ions can reach the substrate easily. It means that in SPC electrodeposition, the metal ion concentration near the cathode, which decreases after the high rate of deposition at the on-time period, can be effectively recovered by ion migration or diffusion during the relatively long off-time period. This fact also justifies the results obtained for the $E_{f}$ values using both electrodeposition processes ${ }^{47}$.

In addition, Table 3 presents the average results concerning the thickness of the DC and SPC coatings. Thin coatings $(<1 \mu \mathrm{m})$ were produced using both DC and SPC processes. The thickness of the coatings, calculated using Equation 3, depends on the density and on the molar mass, considering the metallic contents in each deposited coating. However, the charge used in each case is also depended on the deposited mass (Equation 4). Therefore, considering the low values of deposited mass achieved under the conditions of these experiments (which are also related to the low $E_{f}$ values), the low thickness values obtained for all deposited coatings can be considered as an expected result. Similarly, the coatings prepared using SPC deposition process were thicker than those obtained from a deposition using DC.

The average chemical composition of the DC and SPC coatings (as wt. \% $\mathrm{Cu}$ and wt. \% Co) for each experiment is also shown in Table 3. It can be noted that, independent of the current mode used, normal deposition processes occurred in the experiments performed with the sodium tartrate bath. The values of wt. $\% \mathrm{Cu}$ were always higher than that of the wt. \% Co for all electrodeposition coatings. Moreover, the cobalt content in the coatings was smaller than its ion content in the deposition bath. These results confirm that the deposition of the nobler metal was favored in all studied conditions.

The applied current density and the current mode used to produce the coatings (DC or SPC) affected the chemical composition of the coating. Table 3 shows that, except for the coatings produced under the conditions of Experiment 1 , there is a trend of increasing the values of wt. \% Co and decreasing those of wt. \% $\mathrm{Cu}$ as $\mathrm{j}$ is varied to more cathodic values, when DC was used to produce the coatings. The present results can be related to the $\mathrm{E}_{\mathrm{f}}$ and $\mathrm{h}$ data, indicating that, for the $\mathrm{DC} \mathrm{Cu}$-Co coatings produced using tartrate bath, the increase in cobalt content in the coating is followed by a decrease in the current efficiency and in the thickness of the coatings. This effect can also be related with the increase in HER and/or OER processes at high $\mathrm{j}$ values, which compete with the reduction of the metallic ions.

Considering the SPC coatings, there is no direct relationship between the cobalt content and the applied $\mathrm{j}_{\mathrm{m}}$ values. In the production of alloy coatings using SPC, if mass transfer controls one of the partial reduction reactions, while the other follows Tafel kinetics, the resulting alloy composition can vary strongly with the applied pulse parameters ${ }^{48}$. In a typical electrolyte containing a small concentration of copper ions and an excess of a less noble ion, copper continues to

Table 3. Average values of current efficiency $\left(\mathrm{E}_{\mathrm{f}}, \%\right)$, thickness $(\mathrm{h}, \mathrm{mm})$ and copper and cobalt contents (wt. \% $\mathrm{Cu}$ and wt. \% Co) in the

\begin{tabular}{|c|c|c|c|c|c|c|c|c|c|}
\hline \multicolumn{5}{|c|}{ DC } & \multicolumn{5}{|c|}{ SPC } \\
\hline Exp. no & $E_{f}(\%)$ & $h(\mu \mathrm{m})$ & $\mathrm{Cu}($ wt. \%) & Co (wt. \%) & Exp. no & $E_{f}(\%)$ & $\mathrm{h}(\mu \mathrm{m})$ & $\mathrm{Cu}($ wt. \%) & Co (wt. \%) \\
\hline 1 & 46 & 0.52 & 96.2 & 3.8 & $1^{\prime}$ & 52 & 0.59 & 96.9 & 3.1 \\
\hline 2 & 65 & 0.77 & 98.8 & 1.2 & $2^{\prime}$ & 78 & 0.91 & 98.8 & 1.2 \\
\hline 3 & 61 & 0.71 & 87.4 & 12.6 & 3 ' & 62 & 0.73 & 70.5 & 29.5 \\
\hline 4 & 39 & 0.48 & 71.2 & 28.8 & 4 ' & 46 & 0.52 & 84.1 & 15.9 \\
\hline
\end{tabular}
coatings produced at different $\mathrm{j}$ (or jm) values (Table 1), using DC and SPC. 
reduce at the cathode, under limiting current conditions, during the off time. Due to the difference in the reduction potentials of the two metals, the less noble metal (cobalt, in the present work) dissolves when the applied current pulse was switched off ${ }^{48,49}$. Therefore, in addition to the electrodeposition mechanism in the presence of tartrate ion, the wt. \% Co in the SPC coatings is dependent on the joint effect of $\mathrm{j}_{\mathrm{m}}$ and $\mathrm{t}_{\text {off }}$. Also, at high $\mathrm{j}_{\mathrm{m}}$ values (Experiment $4^{\prime}$ ), the HER or/and ORR processes may have competed with the $\mathrm{Co}$ (II) reduction, decreasing the wt. \% Co in the coating, as well as the total deposited mass. It means that, although the copper content increased, the metallic coating mass, as a whole, decreased, causing a reduction in both $\mathrm{E}_{\mathrm{f}}$ and $\mathrm{h}$ values.

Table 3 also shows that the average cobalt contents for the coating produced under the conditions of Experiments 1 and 1'were higher than those obtained using the conditions of Experiments 2 and 2', respectively for DC and SPC processes. In addition, the $E_{f}$ and $h$ values obtained for the coatings prepared using $\mathrm{j}=\mathrm{j}_{\mathrm{m}}=1.5 \mathrm{~A} \mathrm{~m}^{-2}$ were smaller than those verified for $\mathrm{j}=\mathrm{j}_{\mathrm{m}}=5 \mathrm{~A} \mathrm{~m}^{-2}$, independent of the current mode used. Based on Figure 3, one could suppose that only the reduction of $\mathrm{Cu}$ (II) ions would occur when $\mathrm{j}=\mathrm{j}_{\mathrm{m}}=1.5 \mathrm{~A} \mathrm{~m}^{-2}$ was used to produce the coatings. However, it is possible that the most stable $\mathrm{Cu}$ (II)-tartrate complex could have interfered in the kinetics of the deposition process, making it difficult to reduce the $\mathrm{Cu}$ (II) ions and favoring the cobalt deposition. Therefore, the applied deposition current density had to be increased to overcome this barrier and to enhance the copper deposition.

Based on Table 3, only the coatings produced under the conditions of Experiments 3 and 4 (for DC process) and Experiments 3' and 4' (for SPC process) presented high cobalt content in the coating. Therefore, these coatings were selected to be microstructural, morphological and electrochemically characterized.

\subsection{Characterization of the coatings}

\subsubsection{Microstructural characterization}

Figure 4 presents the diffraction lines for the selected Co-rich $\mathrm{Cu}-\mathrm{Co}$ alloys deposited on iron substrate using DC and SPC processes. It is generally difficult to analyze electrolytically obtained alloy coatings by traditional $\mathrm{X}$-ray examination because these films usually consist of fine crystals, non-uniform in composition and presenting a considerable distortion of the crystal lattice, due to the presence of non-equilibrium phases formed on the cathode at high overpotential values. In some cases, non-cataloged crystalline phases can be obtained ${ }^{50}$.

It is possible to note the high intensity of the diffraction peak related to the steel substrate (PDF 06-0696), independent of the current mode used to produce the coatings. This result is coherent with the small thickness values (h), earlier showed in Table 3. However, the intense peaks observed in the
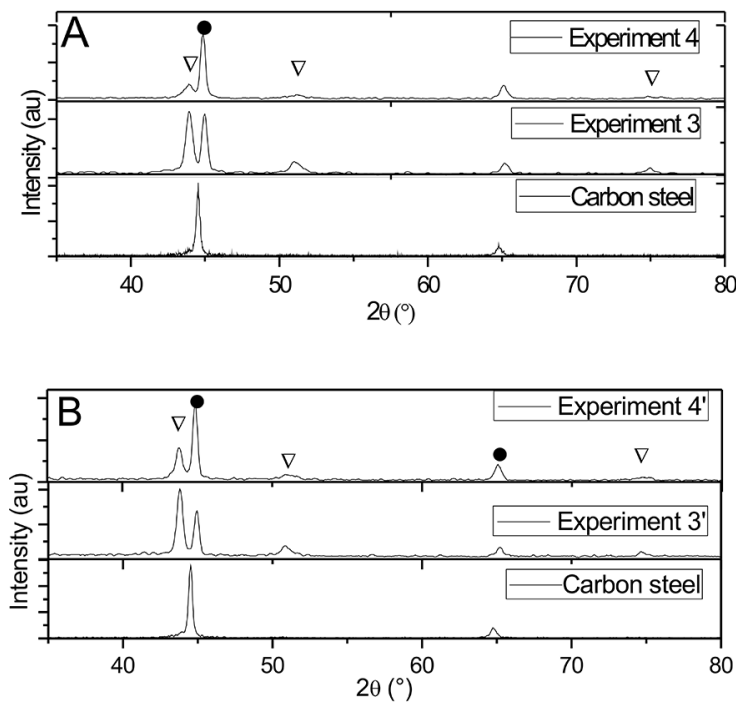

Figure 4. X-rays diffractograms of the $\mathrm{Cu}$-Co coating produced using (A) DC and (B) SPC. Legend: diffraction lines related to $\mathrm{CuCo}(\nabla)$ and $\mathrm{Fe}(\bullet)$ species

diffractograms obtained for both current modes at $2 \theta \sim 43.5^{\circ}$ indicate that the deposited $\mathrm{Cu}$-Co alloys have a preferred (111) orientation ${ }^{15,51,52}$. Cu-Co alloy is supposed to be a metastable phase at room temperature. It is a copper-rich $\mathrm{FCC} \mathrm{Cu}-\mathrm{Co}$ phase with a preferred orientation of (111) planes ${ }^{53}$. Small intensity and large peaks at $2 \theta \sim 50.9^{\circ}$ and $2 \theta \sim 74.6^{\circ}$, also present in both diffractograms, can be related to the $\mathrm{Cu}-\mathrm{Co}$ (200) and $\mathrm{Cu}-\mathrm{Co}$ (220), respectively ${ }^{15,51,54}$. Similar results were found for $\mathrm{Cu}-\mathrm{Co}$ alloy coatings produced with citrate and glycine baths with good anticorrosive properties ${ }^{14,15}$.

Figure $4 \mathrm{~A}$ also shows that the coating produced using $40 \mathrm{~A} \mathrm{~m}^{-2}$ and DC (Experiment 4) presented a small and distorted $\mathrm{CuCo}$ (111) peak. This result can be related to the decrease in the crystallinity of the coating (and in its grain size), as $\mathrm{j}$ (and the wt. \% Co in the coating) increased. A decrease in this peak intensity can also be seen in Figure 4B for the coating produced using $\mathrm{j}_{\mathrm{m}}=40 \mathrm{~A} \mathrm{~m}^{-2}$ and SPC mode. In this case, this effect can be also associated to the current mode used ${ }^{48}$.

It is known that the solubility limit of the $\mathrm{Cu}-\mathrm{Co}$ solid solution at room temperature is very low in the equilibrium state, as proposed by the $\mathrm{Cu}-\mathrm{Co}$ phase diagram ${ }^{52,55,56}$. Moreover, the joint deposition of $\mathrm{Cu}$ and $\mathrm{Co}$ cannot produce thermodynamically stable binary $\mathrm{Cu}-\mathrm{Co}$ systems in the concentration range between 12 at. $\% \mathrm{Cu}$ and 95 at. $\% \mathrm{Cu}^{57}$. The coatings produced in the present work have at. $\% \mathrm{Cu}$ ranging between 69 at. $\% \mathrm{Cu}$ and 86 at. $\% \mathrm{Cu}$. Therefore, it is more likely that the coatings were composed by a supersaturated metastable solid solution of $\mathrm{Cu}$ and $\mathrm{Co}$, as has already been observed in the literature ${ }^{51}$. However, no segregated phase could be detected by the used technique for both DC and SPC coatings. These results confirm the limitations of conventional XRD for investigating the non- 
homogeneities in $\mathrm{Cu}-\mathrm{Co}$ solid solutions, mainly when low thickness films are formed ${ }^{54}$.

\subsubsection{Morphological characterization}

Figure 5 presents the micrographs of the coatings produced using DC and SPC under the conditions used for the selected experiments. It is possible to note that, in both cases, the grain size decreased as the applied current density was increased. This result corroborates the decrease of $\mathrm{Cu}-\mathrm{Co}$ (111) peak intensity verified for these coatings (Figure 4), confirming that a decrease in the crystallinity of the coatings were observed under these conditions.

Although presenting different chemical compositions, homogeneous and apparently porous morphologies, composed by agglomerated small grains, were produced when $15 \mathrm{~A} \mathrm{~m}^{-2}$ was used to electrodeposit $\mathrm{Cu}-\mathrm{Co}$ coatings, independent of the current mode used (Figures 5A and 5C, for Experiments 3 and 3', respectively). On the other hand, coatings presenting compact morphologies and smaller grain sizes were produced using $40 \mathrm{~A} \mathrm{~m}^{-2}$ (Figures 5B and 5D, for Experiments 4 and 4', respectively). In this case, however, the surface morphologies obtained for the DC and SPC coatings were very different. While the DC coating presents needle-form grains and several leaf-like agglomerates on its surface (Figure 5B), the one prepared using SPC (Figure 5D) shows small spherical grains.

It is important to mention that the grain size of both coatings produced by SPC seemed to be smaller than those prepared using DC. The decrease in grain size can be related to the increase in cobalt content in the coating ${ }^{58}$. Although this effect is clearly seen in the present work for the DC coatings (Figure 5B and Table 3), it was not observed for the SPC coatings. More refined-grains coatings are usually obtained when SPC is used to produce metallic coatings ${ }^{34}$. In the present experiments, the SPC effect is seen for both current densities studied, which also present high cobalt contents (Figures 5C and 5D). In addition, the small values of the deposited mass and the thickness of the coating obtained using $\mathrm{j}_{\mathrm{m}}=40 \mathrm{~A} \mathrm{~m}^{-2}$ (Figure 5D), may have contributed to the smallest grain size observed for this coating.

\subsubsection{Electrochemical characterization}

The anticorrosive performance of the selected Co-rich $\mathrm{Cu}-\mathrm{Co}$ coatings produced using DC and SPC were evaluated in $\mathrm{NaCl} 0.5 \mathrm{~mol} \mathrm{~L}^{-1}$ by EIS. The Nyquist diagrams of the bare carbon steel substrate and the coating/substrate systems prepared using $\mathrm{j}=\mathrm{j}_{\mathrm{m}}=15 \mathrm{~A} \mathrm{~m}^{-2}$ and $\mathrm{j}=\mathrm{j}_{\mathrm{m}}=40 \mathrm{~A} \mathrm{~m}^{-2}$, for both current modes, are presented in Figure 6.

The diameters of the capacitive loops in the Nyquist diagrams can be considered as an indication of the corrosion resistance of the coating/substrate system in the aggressive medium. Therefore, it is possible to note, in Figure 6A, that the coating/substrate system produced under the condition of Experiment 3 (DC and $\mathrm{j}=15 \mathrm{~A} \mathrm{~m}^{-2}$ ) presents a better anticorrosive performance than that prepared using the conditions of Experiment 3' ( $\mathrm{SPC}$ and $\left.\mathrm{j}_{\mathrm{m}}=15 \mathrm{~A} \mathrm{~m}^{-2}\right)$.
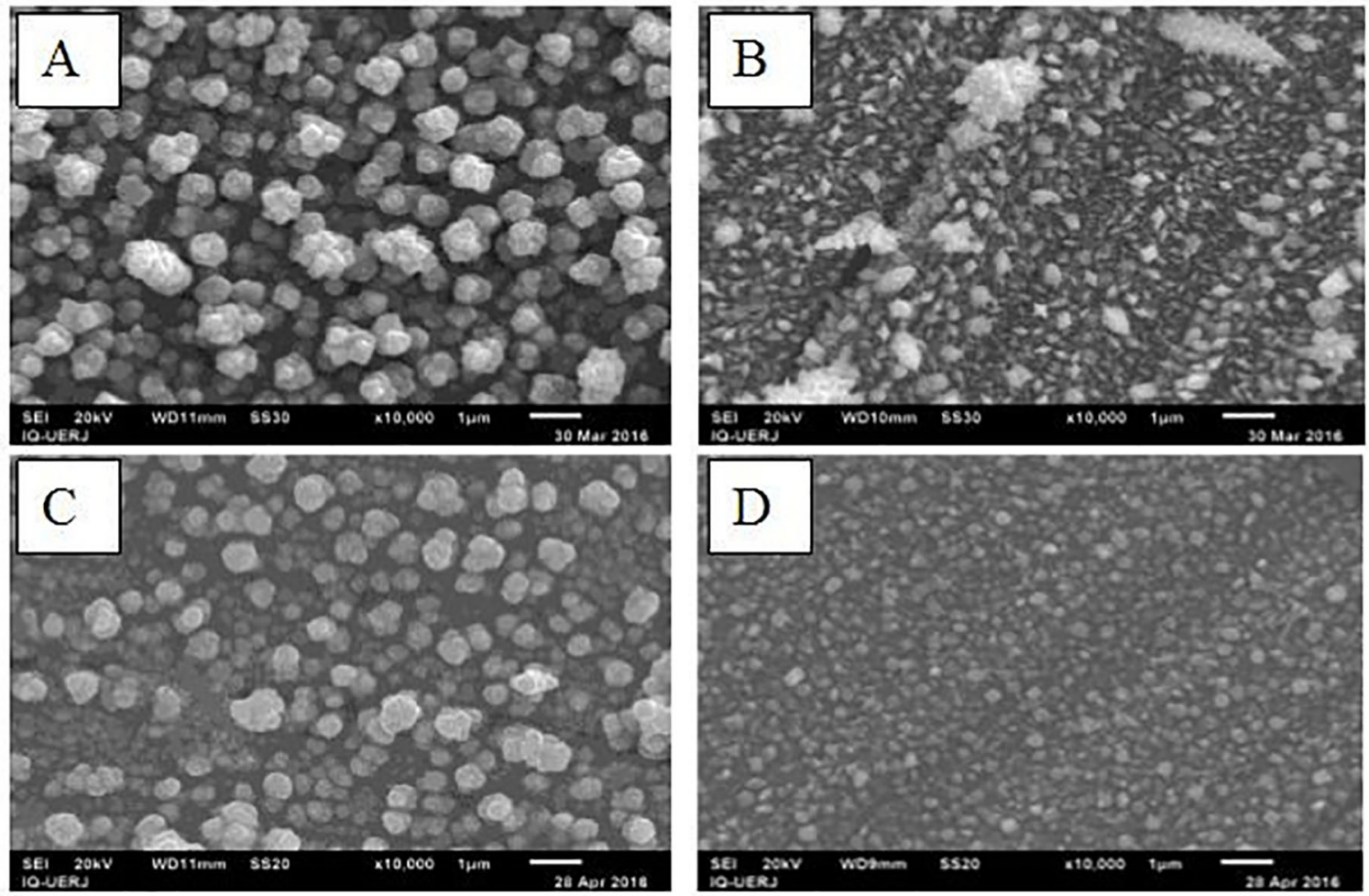

Figure 5. Surface morphology evaluation of the Cu-Co coatings produced at using DC (A, B) and SPC (C, D): (A) Experiment 3, (B) Experiment 4; (C) Experiment 3'; (D) Experiment 4'. Magnification: 10000X 
In opposition, Figure 6B shows that the best result was obtained for the coating/substrate system produced using Experiment 4' $\left(\mathrm{SPC}\right.$ and $\left.\mathrm{j}_{\mathrm{m}}=40 \mathrm{~A} \mathrm{~m}^{-2}\right)$. In fact, the diameter of the capacitive loop of the system prepared by DC and $j=$ $40 \mathrm{~A} \mathrm{~m}^{-2}$ is smaller than that observed for the bare substrate, suggesting that this coating could not protect the substrate in the studied medium.

The EIS data were simulated using the equivalent electric circuits presented in Figure 7. The simulation adjustment was considered satisfactory for an error value less than $1 \%{ }^{59}$. The circuit shown in Figure 7A was used to simulate the data obtained from Experiments 3, 3' and 4'. In this circuit, $\mathrm{R}_{\mathrm{S}}$ represents the solution resistance, $\mathrm{R}$ is the charge transfer resistance $\left(\mathrm{R}_{\mathrm{ct}}\right)$, and CPE represents the constant phase element associated with the electric double layer capacitance of the $\mathrm{Cu}-\mathrm{Co}$ film.

However, this circuit did not provide an efficient simulation for the EIS data obtained from Experiment and 4. Lima et al. ${ }^{15}$ have shown that Co-rich Cu-Co coatings may present a $\mathrm{Co}(\mathrm{OH})_{2}$ layer on the surface, due to the polarization of the electrode in the alkaline bath used to produce them. Although all coatings were prepared using the same alkaline tartrate bath and this $\mathrm{Co}(\mathrm{OH})_{2}$ layer could be present on their surface, several leaf-like agglomerates could be observed only on the surface of the DC produced coatings presented in Figure 5B. It could be related to the presence of an external and nonhomogeneous $\mathrm{Co}(\mathrm{OH})_{2}$ layer on its surface. Therefore, the serial circuit presented in Figure 7B, which consists of two R-CPE element (resistance - constant phase element) and the solution resistance $\left(\mathrm{R}_{\mathrm{S}}\right)$ in series, was used to simulate the EIS data from Experiment 4 and a decrease in the simulation error was obtained. In this circuit, the first
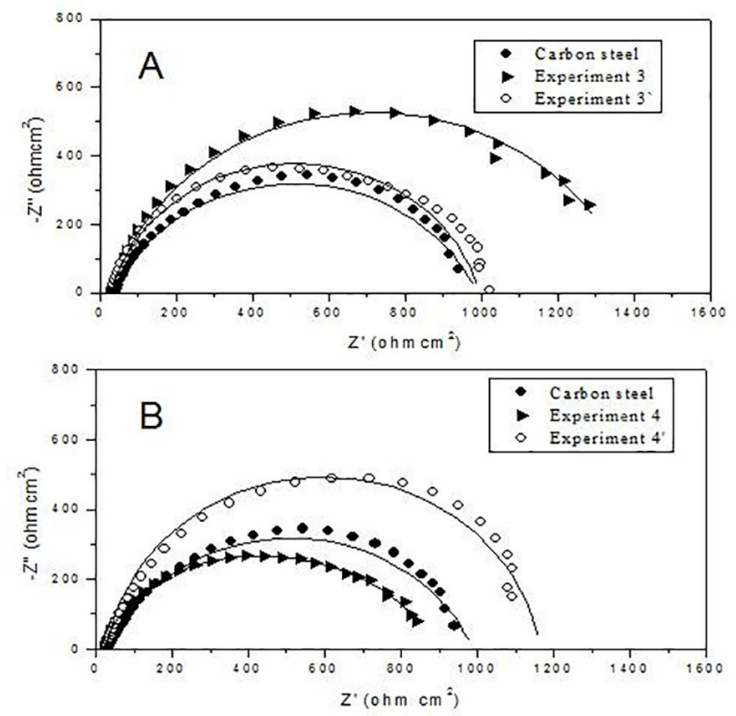

Figure 6. Nyquist diagrams for Co-rich $\mathrm{Cu}-\mathrm{Co}$ coating/carbon steel substrates in $\mathrm{NaCl} 0.5 \mathrm{~mol} \mathrm{~L}^{-1}$ under the conditions of (A) Experiments 3 and $3^{\prime}\left(\mathrm{j}=\mathrm{jm}=15 \mathrm{~A} \mathrm{~m}^{-2}\right.$, using DC and $\mathrm{SPC}$, respectively) and (B) Experiments 4 and $4^{\prime}\left(\mathrm{j}=\mathrm{jm}=40 \mathrm{Am}^{-2}\right.$, using $\mathrm{DC}$ and SPC, respectively)
A
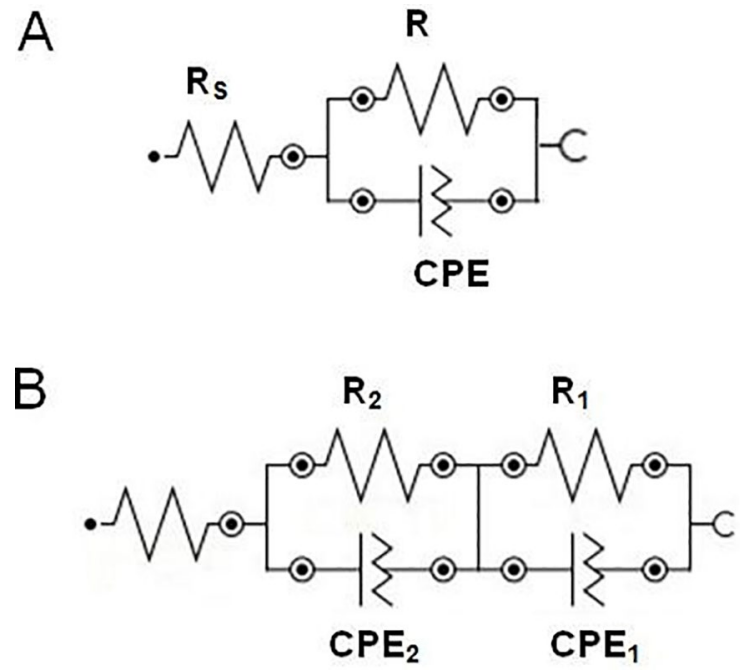

Figure 7. Equivalent circuit model used to simulate the EIS data of the selected systems. (A) Carbon steel substrate, Experiments 3, 3'and 4'; (B) Experiment 4

time constant $\left(\mathrm{R}_{1}-\mathrm{CPE}_{1}\right)$ is related to the $\mathrm{Cu}$-Co coating and the second one $\left(\mathrm{R}_{2}-\mathrm{CEE}_{2}\right)$, with the external $\mathrm{Co}(\mathrm{OH})_{2}$ layer. In this case, the $R_{c t}$ value was obtained by the sum of $R_{1}+R_{2}$.

The simulated data, presented in Table 4, confirm what was previously verified in Figure 6. It is seen that the systems prepared under the conditions of Experiments 3 and 4' present the highest $\mathrm{R}_{\mathrm{ct}}$ values among the selected Co-rich $\mathrm{Cu}$-Co coating/substrate systems. In addition, these systems present low $\mathrm{C}_{\mathrm{dl}}$ values, indicating that these coatings show low tendency to conduct charge ${ }^{60,61}$. Even though the system prepared using the conditions of Experiment 3' also presented a small $\mathrm{C}_{\mathrm{dl}}$ value, its $\mathrm{R}_{\mathrm{ct}}$ value is near that of the bare carbon steel. The coating/substrate system produced under the conditions of Experiment 4 shows the worse results.

Although both coatings prepared using $15 \mathrm{Am}^{-2}$ (Experiments 3 and 3') showed a loose morphology (Figures 5A and 5C), the coating produced by SPC process seems to be more porous than that obtained by DC, which could have contributed to its worse anticorrosive performance. On the other hand, those coatings prepared using $40 \mathrm{~A} \mathrm{~m}^{-2}$ (Experiments 4 and 4') were more compact (Figures 5B and 5D). However, the needle-form grains and the loose alkaline layer deposited on the coating produced by DC may not cover the substrate completely. In addition, there is a crack on the surface of this coating, which could have permitted the attack of the substrate by the electrolyte.

In addition, all the coatings presented different chemical compositions, depending on the current density and on the current mode (Table 3). The results in Figure 6 and Table 4 indicate that the chemical composition of the coatings affected their anticorrosive characteristics in a greater extent. In the present work, the anticorrosive coatings produced using Experiments 3 and 4' present 12.6 and 15.9 wt. \% Co, respectively, while those containing higher wt. \% Co could 
Table 4. $\mathrm{R}_{\mathrm{ct}}$ and $\mathrm{C}_{\mathrm{dl}}$ values obtained by simulating the EIS data ( Figure 6 ) using the equivalent circuits presented in Figure 7

\begin{tabular}{ccccc}
\hline Exp. no & $\mathbf{R}_{\mathbf{e}}(\boldsymbol{\Omega})$ & $\begin{array}{c}\mathbf{R}_{\mathrm{ct}} \\
\left(\boldsymbol{\Omega} \mathbf{c m}^{-2}\right)\end{array}$ & $\begin{array}{c}\mathbf{C}_{\mathrm{dl}} \\
\left(\boldsymbol{\mu} \mathbf{F} \mathbf{~ c m}^{-2}\right)\end{array}$ & $\mathbf{N}$ \\
\hline $\begin{array}{c}\text { Bare } \\
\text { carbon } \\
\text { steel }\end{array}$ & 6.31 & 960.4 & $1.59 \times 10^{-3}$ & 0.746 \\
3 & 5.14 & 1370 & $1.86 \times 10^{-3}$ & 0.837 \\
4 & 4.48 & 784 & $5.51 \times 10^{-2}$ & 0.810 \\
3, & 5.66 & 966 & $7.52 \times 10^{-4}$ & 0.847 \\
$4^{\prime}$ & 5.64 & 1137 & $1.40 \times 10^{-3}$ & 0.910 \\
\hline
\end{tabular}

not protect the substrate adequately. Anticorrosive Co-rich $\mathrm{Cu}$-Co coatings, produced from citrate and glycinate baths using DC, were obtained for wt. $\%$ Co $\sim 40^{8,15}$. In these works, however, some deposition parameters, such as current density, stirring speed and bath $\mathrm{pH}$, were simultaneously varied employing experimental design ${ }^{62}$, and the coatings were produced using deposition parameters values that were different from those used in this work. Therefore, under the present conditions, the current results suggest that a limited value of cobalt content must be present in the coating to enhance the anticorrosive properties of the studied coating/ substrate systems.

\subsubsection{Stability of the coatings}

Considering the results presented in Figure 6 and Table 4, the $\mathrm{Co}$-rich $\mathrm{Cu}$-Co coating/substrate systems produced under the conditions of Experiments 3 and 4' were selected to be evaluated by EIS after $24 \mathrm{~h}$ immersed in the electrolyte $(\mathrm{NaCl}$ $0.5 \mathrm{~mol} \mathrm{~L}^{-1}$ ). The Nyquist diagrams presented in Figure 8 shows the capacitive loops obtained in this experiment. The results observed for the bare steel substrate and for the same systems after $1 \mathrm{~h}$ of exposure in the aggressive medium are also presented, for comparison.

It is possible to observe an increase in the diameter of the capacitive loop of both systems after $24 \mathrm{~h}$ of immersion, indicating an enhancement in the anticorrosive performance of these coating/substrate systems. In a saline medium, the main cathodic reaction is the reduction of dissolved oxygen (ORR), earlier shown in Equation 9. However, the $\mathrm{H}^{+}$reduction from the water (HER), shown in Equation 8, cannot be forgotten, mainly under non-polarized conditions, such as those used in the EIS measurements. Both reactions cause an increase in the alkalinity of the interface electrode, which may have enabled the stability of any cobalt oxides or hydroxides that could have been generated earlier on the surface of the electrode, during the electrodeposition process ${ }^{63}$. The presence of stable $\mathrm{Co}(\mathrm{OH})_{2}$ layers on the surface of the coatings may have acted as a physical barrier, decreasing the $\mathrm{O}_{2}$ mass transport to the surface of the electrode ${ }^{15}$.

The EIS data of the coating/substrate systems immersed in $\mathrm{NaCl} 0.5 \mathrm{~mol} \mathrm{~L}^{-1}$ for $24 \mathrm{~h}$ were simulated using the
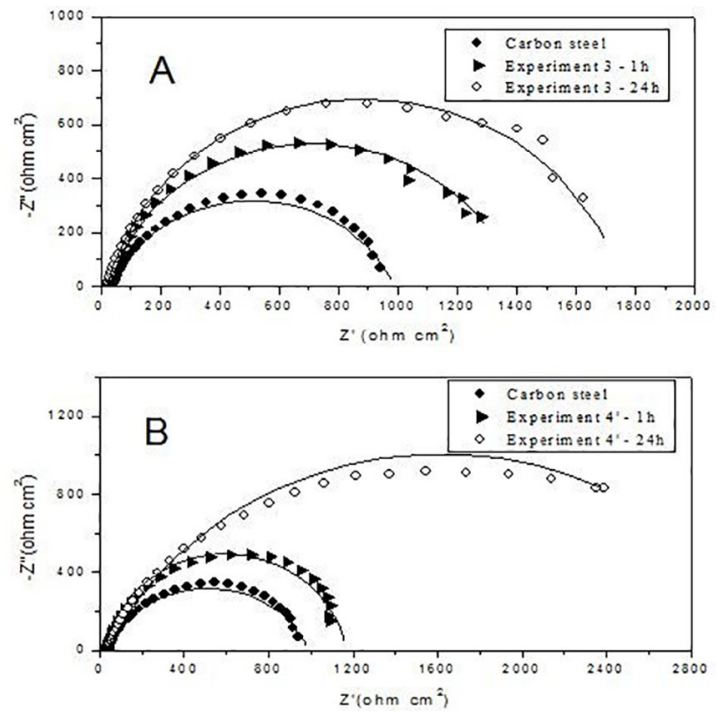

Figure 8. Nyquist diagrams for Co-rich $\mathrm{Cu}$-Co coating/carbon steel substrates immersed in $\mathrm{NaCl} 0.5 \mathrm{~mol} \mathrm{~L}^{-1}$ for $1 \mathrm{~h}$ and $24 \mathrm{~h}$. (A) Experiment $3\left(\mathrm{j}=15 \mathrm{~A} \mathrm{~m}^{-2}\right.$, using DC) and (B) Experiment 4' $\left(\mathrm{j}_{\mathrm{m}}=40 \mathrm{~A} \mathrm{~m}^{-2}\right.$, using SPC)

Table 5. $\mathrm{R}_{\mathrm{ct}}$ and $\mathrm{C}_{\mathrm{dl}}$ values obtained by simulating the EIS data (Figure 8) using the equivalent circuit presented in Figure 7A

\begin{tabular}{ccccc}
\hline Exp. no & $\mathbf{R}_{\mathbf{s}}(\boldsymbol{\Omega})$ & $\begin{array}{c}\mathbf{R}_{\mathrm{ct}} \\
\left(\boldsymbol{\Omega} \mathbf{c m}^{-2}\right)\end{array}$ & $\begin{array}{c}\mathbf{C}_{\mathrm{dl}} \\
\left(\boldsymbol{\mu} \mathbf{F} \mathbf{~ c m}^{-2}\right)\end{array}$ & $\mathbf{N}$ \\
\hline 3 & 4.78 & 1730 & $2.76 \times 10^{-3}$ & 0.862 \\
$4^{\prime}$ & 5.31 & 3150 & $4.79 \times 10^{-3}$ & 0.725 \\
\hline
\end{tabular}

equivalent circuit presented in Figure 7A and these results are shown in Table 5.

It can be noted that, the $\mathrm{R}_{\mathrm{ct}}$ values obtained for the systems produced using the conditions of Experiments 3 and 4' were, respectively, $64 \%$ and $21 \%$ higher than the values obtained after $1 \mathrm{~h}$ of exposure in the same medium for each system. This result could be associated with their different morphologies and grain sizes. The coating related to the conditions of Experiment 4' was prepared by SPC, which generally causes a decrease in the grain size. In addition, the cobalt content in this coating is higher than in the coating prepared under the conditions of Experiment 3, which could have contributed to the decrease in the grain size due to the refining effect of cobalt in electrodeposited coatings ${ }^{58}$.

\section{Conclusions}

Spectrophotometric experiments confirmed that $\mathrm{Cu}$ (II)tartrate and $\mathrm{Co}$ (II)-tartrate complexes are produced in a solution containing both metallic ions and tartrate ions, at $\mathrm{pH}$ 8.3. Also, comparing to their respective aqueous complexes, this result suggests that the $\mathrm{Cu}$ (II)-tartrate complex is more stable than the Co(II)-tartrate one, which may have influenced on their reduction process. The voltammetric results corroborated this 
statement, indicating that, under the conditions used in this work, the reduction of $\mathrm{Cu}$ (II) ions is disfavored, while the reduction of Co (II) is favored when a solution containing tartrate as the complexing agent was used, which may have contributed to produce $\mathrm{Cu}-\mathrm{Co}$ alloy coatings.

The applied current density and the current mode (DC and SPC) affected both the current efficiency and the chemical composition of the $\mathrm{Cu}-\mathrm{Co}$ alloy coatings prepared using sodium tartrate as a ligand. Co-rich $\mathrm{Cu}-\mathrm{Co}$ alloy coatings were produced, by both DC and SPC processes, when $\mathrm{j}=\mathrm{j}_{\mathrm{m}}=15 \mathrm{~A} \mathrm{~m}^{-2}$ and $\mathrm{j}=\mathrm{j}_{\mathrm{m}}=40 \mathrm{~A} \mathrm{~m}^{-2}$ were used. The morphology of these selected coatings was also influenced by the current density and the current mode, and those produced using $\mathrm{j}_{\mathrm{m}}=40 \mathrm{~A} \mathrm{~m}^{-2}$ (SPC mode) presented a compact morphology and small grain sizes.

The electrochemical evaluation of the selected coating/ substrate systems showed that only those prepared under the conditions of Experiment $3\left(\mathrm{j}=15 \mathrm{~A} \mathrm{~m}^{-2}\right.$, using DC) and Experiment 4' $\left(\mathrm{j}_{\mathrm{m}}=40 \mathrm{~A} \mathrm{~m}^{-2}\right.$, using SPC) could be considered as protective systems. In addition, the charge transfer resistances of these coating/substrate systems were improved after immersion in $\mathrm{NaCl} 0.5 \mathrm{~mol} \mathrm{~L}^{-1}$ for $24 \mathrm{~h}$, suggesting that both coatings could be used for long-term applications in this aggressive medium.

The conditions used in this work state that the SPC coating produced using $\mathrm{j}_{\mathrm{m}}=40 \mathrm{~A} \mathrm{~m}^{-2}$ show the most favorable characteristics (15.9 wt. \% Co, compact morphology, smallest grain size and the highest $\mathrm{R}_{\mathrm{ct}}$ value after $24 \mathrm{~h}$ exposure in the saline corrosive medium) to be used as a protective coating for carbon steel in $\mathrm{NaCl} 0.5 \mathrm{~mol} \mathrm{~L}^{-1}$.

\section{Acknowledgements}

The authors would like to thank the Rio de Janeiro Research Foundation (FAPERJ), the Brazilian National Research Council (CNPq), the State University of Rio de Janeiro (UERJ), and the Prociência Program for financial support. We would like also to thank M.Sc. Antônio Vitor de Castro Braga for technical support, Diego Barros (LEAM/ UERJ) for the chemical analysis and Isaac Mallet (LabMEV/ UERJ) for the SEM analysis.

\section{References}

1. Cohen-Hyams T, Kaplan WD, Aurbach D, Cohen YS, Yahalom J. Electrodeposition of Granular Cu-Co Alloys. Journal of the Electrochemical Society. 2003;150(1):C28-C35.

2. Jyoko Y, Kashiwabara S, Hayashi Y. Preparation of Giant Magnetoresistance $\mathrm{Co}-\mathrm{Cu}$ Heterogeneous Alloys by Electrodeposition. Journal of the Electrochemical Society. 1997;144(7):L193-L195.

3. Jyoko Y, Kashiwabara S, Hayashi Y. Preparation of Giant Magnetoresistance $\mathrm{Co} / \mathrm{Cu}$ Multilayers by Electrodeposition. Journal of the Electrochemical Society. 1997;144(1):L5-L8.
4. Gündel A, Chassaing E, Schmidt JE. In situ magnetization measurements of $\mathrm{Cu} / \mathrm{Co}$ multilayers during the process of electrodeposition. Journal of Applied Physics. 2001;90(10):52575260 .

5. Souza TM, Senna LF, do Lago DCB. Eletrodeposição de revestimentos de ligas metálicas contendo cobre e cobalto empregando um eletrólito ambientalmente amigável. In: Anais do XXII CBECIMAT - Congresso Brasileiro de Engenharia e Ciência dos Materiais; 2016 Nov 6-10; Natal, RN, Brasil. p. 6840-6851.

6. Gu S, Atanasova A, Hampden-Smith MJ, Kodas TT. Chemical vapor deposition of copper-cobalt binary films. Tin Solid Films. 1999;340(1-2):45-52.

7. Ghosh SK, Bera T, Saxena C, Bhattacharya S, Dey GK. Effect of pulse plating and additive on phase separation in $\mathrm{Cu}-\mathrm{Co}$ nano-granular alloys. Journal of Alloys and Compounds. 2009;475(1-2):676-682.

8. Silva FLG, Garcia JR, Cruz VGM, Luna AS, Lago DCB, Senna LF. Response surface analysis to evaluate the influence of deposition parameters on the electrodeposition of $\mathrm{Cu}-\mathrm{Co}$ alloys in citrate medium. Journal of Applied Electrochemistry. 2008;38(12):1763-1769.

9. Berkowitz AE, Mitchell JR, Carey MJ, Young AP, Zhang S, Spada FE, et al. Giant magnetoresistance in heterogeneous Cu-Co alloys. Physical Review Letters. 1992;68(25):3745.

10. Vagramyan AT, Solov'eva ZA. Technology of Electrodeposition. Teddington: Robert Draper; 1961.

11. Senna LF, Díaz SL, Sathler L. Electrodeposition of copper-zinc alloys in pyrophosphate-based electrolytes. Journal of Applied Electrochemistry. 2003;33(12):1155-1161.

12. Johannsen K, Page D, Roy S. A systematic investigation of current efficiency during brass deposition from a pyrophosphate electrolyte using RDE, RCE and QCM. Electrochimica Acta. 2000;45(22-23):3691-3702.

13. Fujiwara Y, Enomoto H. Electrodeposition of ß-Brass from Cyanide Baths with Accumulative Underpotential Deposition of Zn. Journal of the Electrochemical Society. 2000;147(5):18401846.

14. de Farias LT, Luna AS, do Lago DCB, de Senna LF. Influence of cathodic current density and mechanical stirring on the electrodeposition of $\mathrm{Cu}-\mathrm{Co}$ alloys in citrate bath. Materials Research. 2008;11(1):1-9.

15. de Lima TG, Rocha BCCA, Braga AVC, do Lago DCB, Luna AS, Senna LF. Response surface modeling and voltammetric evaluation of Co-rich $\mathrm{Cu}-\mathrm{Co}$ alloy coatings obtained from glycine baths. Surface and Coatings Technology. 2015;276:606-617.

16. Jung M, Lee G, Choi J. Electrochemical plating of $\mathrm{Cu}-\mathrm{Sn}$ alloy in non-cyanide solution to substitute for $\mathrm{Ni}$ undercoating layer. Electrochimica Acta. 2007;241:229-236.

17. Garcia JR, do Lago DCB, de Senna LF. Electrodeposition of Cobalt Rich Zn-Co alloy Coatings from Citrate Bath. Materials Research. 2014;17(4):947-957.

18. Mohamed AE, Rashwan SM, Abdel-Wahaab SM, Kamel MM Electrodeposition of $\mathrm{Co}-\mathrm{Cu}$ alloy coatings from glycinate baths. Journal of Applied Electrochemistry. 2003;33(11):1085-1092. 
19. López Antón R, Fdez-Gubieda ML, García-Arribas A, Herreros $\mathrm{J}$, Insausti M. Preparation and characterisation of $\mathrm{Cu}-\mathrm{Co}$ heterogeneous alloys by potentiostatic electrodeposition. Materials Science and Engineering: A. 2002;335(1-2):94100.

20. Song CH, Choi Y, Lee JY, Kim M. Electromagnetic insulating behavior of thin multilayered copper-nickel composite mesh sheet formed by two-step pulse electroplating. The Physics of Metals and Metallography. 2014;115(13):1275-1280.

21. Bauliukienè V, Survilienè A, Survila A. Electroreduction of $\mathrm{Cu}(\mathrm{II})$-tartrate complexes in acid media. Chemija (Vilnius). 2001;12(3):216-220.

22. Abd El Rehim SS, El Ayashy ME. Effect of some plating variables on the electrodeposition of $\mathrm{Cu}-\mathrm{Zn}$ alloys from alkaline tartrate baths. Journal of Applied Electrochemistry. 1978;8(1):33-39.

23. Ballesteros JC, Chainet E, Ozil P, Meas Y, Trejo G. Electrodeposition of Copper from Non-Cyanide Alkaline Solution Containing Tartrate. International Journal of Electrochemistry Science. 2011;6:2632-2651.

24. Casella IG. Electrodeposition of cobalt oxide ? $1 \mathrm{~ms}$ from carbonate solutions containing Co(II)-tartrate complexes. Journal of Electroanalytical Chemistry. 2002;520(1-2):119-125.

25. Teh SH, Yaacob II. Synthesis and characterization of Fe-Pt and Co-Fe-Pt nanocrystalline magnetic thin films electrodeposited from tartrate-alkaline electrolyte solution. Materials Research Innovations. 2011;15(3):196-201.

26. Melo LC, de Lima Neto P, Correia AN. The in?uence of citrate and tartrate on the electrodeposition and surface morphology of $\mathrm{Cu}-\mathrm{Ni}$ layers. Journal of Applied Electrochemistry. 2011;41(4):415-422.

27. Carlos IA, Bidoia ED, Pallone EMJA, Almeida MRH, Souza CAC. Effect of tartrate content on aging and deposition condition of copper-tin electrodeposits from a non-cyanide acid bath. Surface and Coatings Technology. 2002;157(1):14-18.

28. Puippe JC, Leaman F, eds. Theory and Practice of Pulse Plating. Orlando: American Electroplaters and Surface Finishers Society; 1986.

29. Chandrasekar MS, Pushpavanam M. Pulse and pulse reverse plating-Conceptual, advantages and applications. Electrochimica Acta. 2008;53(8):3313-3322.

30. Mohan S, Raj V. The effect of additives on the pulsed electrodeposition of copper. Transactions of the IMF. 2005;83(4):194-198.

31. Beattie SD, Dahn JR. Single Bath, Pulsed Electrodeposition of Copper-Tin Alloy Negative Electrodes for Lithium-ion Batteries. Journal of the Electrochemical Society. 2003;150(7):A894-A899.

32. Mangolini F, Magagnin L, Cavallotti PL. Pulse plating of sacrificial $\mathrm{Mn}-\mathrm{Cu}$ alloys from sulphate bath. Transactions of the IMF. 2007;85(1):27-33.

33. Mangolini F, Magagnin L, Cavallotti PL. Pulse Plating of Mn$\mathrm{Cu}$ Alloys on Steel. Journal of the Electrochemical Society. 2006;153(9):C623-C628.

34. Ghosh SK, Grover AK, Dey GK, Totlani MK. Nanocrystalline $\mathrm{Ni}-\mathrm{Cu}$ alloy plating by pulse electrolysis. Surface and Coatings Technology. 2000;126(1):48-63.
35. Anuar K, Zainal Z, Saravanan N, Asikin N. Preparation of zinc-sulfide thin films in the presence of sodium tartrate as a complexing agent. Materials Science. 2008;44(2):290-293.

36. Cheh HY. Electrodeposition of Gold by Pulsed Current. Journal of the Electrochemical Society. 1971;118(4):551-557.

37. Ghosh SK, Dogra A, Srivastava C, Gupta SK. Effect of annealing and additive agent on magnetoresistance properties of pulse plated Cu-Co nano-granular alloys. Journal of Alloys and Compounds. 2010;504(2):452-456.

38. Garcia JR, do Lago DCB, Cesar DV, Senna LF. Pulsed cobaltrich Zn-Co alloy coatings produced from citrate baths. Surface and Coatings Technology. 2016;306(Pt B):462-472.

39. Silva PS, de Senna LF, do Lago DCB. Cu-Sn Coatings Produced Using Environmentally Non-Aggressive Electrolyte Containing Sodium Tartrate. Materials Research. 2017;20(Suppl 2):667675.

40. Chandrasekar MS, Shanmugasigamani, Pushpavanam M. Morphology and texture of pulse plated zinc-cobalt alloy. Material Chemistry and Physics. 2009;115(2-3):603-611.

41. Hirschorn B, Orazem ME, Tribollet B, Vivier V, Frateur I, Musiani M. Determination of effective capacitance and film thickness from constant-phase-element parameters. Electrochimica Acta. 2010;55(21):6218-6227.

42. Skoog DA, Holler FJ, Nieman TA. Princípios de Análise Instrumental. $5^{\mathrm{a}}$ ed. Porto Alegre: Bookman; 2002. p. 276-287.

43. Santos JS, Trivinho-Strixino F, Pereira EC. Investigation of $\mathrm{Co}(\mathrm{OH})_{2}$ formation during cobalt electrodeposition using a chemometric procedure. Surface and Coatings Technology. 2010;205(7):2585-2589.

44. Liu Y, Wang W. Investigation on the $\mathrm{Cu}(\mathrm{II})$ and $\mathrm{Co}(\mathrm{II})$ Electrochemical Reduction Process in Citrate Solution by CV and EIS. Journal of the Electrochemical Society. 2012;159(6):D375-D381.

45. Khunur MM, Prananto YP. Synthesis and Structure of 2D Cobalt(II)-tartrate Hydrate Coordination Polymers Crystallised from Aqueous Solution. Bulletin of Chemical Reaction Engineering \& Catalysis. 2018;13(2):213-219.

46. Lin FHJ, Horváth C. Measurement of stability constants for complexes of divalent cations with tartaric acid by ion chromatography. Journal of Chromatography A. 1992;589(12):185-195.

47. Meng G, Sun F, Wang S, Shao Y, Zhang T, Wang F. Effect of electrodeposition parameters on the hydrogen permeation during $\mathrm{Cu}-\mathrm{Sn}$ alloy electrodeposition. Electrochimica Acta. 2010;55(7):2238-2245.

48. Landolt D, Marlot A. Microstructure and composition of pulseplated metals and alloys. Surface and Coatings Technology. 2003;169-170:8-13.

49. Sudipta R, Landolt D. Effect of Off-Time on the Composition of Pulse-Plated Cu-Ni Alloys. Journal of the Electrochemical Society. 1995;142(9):3021-3027.

50. Sienna LF, Achete CA, Hirsch T, Mattos O. Characterisation of PVD TiCN layers by physical and electrochemical methods. Surface Engineering. 2005;21(2):144-150. 
51. Pattanaik GR, Pandya DK, Kashyap SC. Preparation of Cu-Co Alloy Thin Films on n-Si by Galvanostatic DC Electrodeposition. Journal of the Electrochemical Society. 2002;149(7):C363-C369.

52. Yuasa M, Kajikawa M, Hakamada M, Mabuchi M. Saturation magnetization in supersaturated solid solution of $\mathrm{Co}-\mathrm{Cu}$ alloy. Applied Physics Letters. 2009;95(16):162502.

53. Zhukova V, Garcia C, del Val JJ, Ilyn M, Granovsky A, Zhukov A. Magnetic and transport properties of Co-Cu microwires with granular structure. Thin Solid Films. 2013;543:142-147.

54. Michaelsen C. On the structure and homogeneity of solid solutions: The limits of conventional X-ray diffraction. Philosophical Magazine A. 1995;72(3):813-828.

55. Hansen M, Elliott RP, Shunk FA; Research Institute. Constitution of binary alloys. New York: McGraw-Hill; 1958.

56. Massalski TB, Okamoto H, Subramanian PR, Kacprzak L, eds. Binary Alloy Phase Diagrams. 2nd ed. Materials Park: ASM; 1990.

57. Kellner E. Magnetic Moment of Co-Cu Solid Solutions with 40\% Co 85\% Cu. Journal of Applied Physics. 1962;33(3):1355.

58. Chai Z, Jiang C, Zhao Y, Wang C, Zhu K, Cai F. Microstructural characterization and corrosion behaviors of $\mathrm{Ni}-\mathrm{Cu}-\mathrm{Co}$ coatings electrodeposited in sulphate-citrate bath with additives. Surface and Coatings Technology. 2016;307(Pt A):817-824.
59. Bayoudh S, Othmane A, Ponsonnet L, Ouada HB. Electrical detection and characterization of bacterial adhesion using electrochemical impedance spectroscopy-based flow chamber. Colloids and Surfaces A: Physicochemical and Engineering Aspects. 2008;318(1-3):291-300.

60. Alexander CL, Tribollet B, Orazem ME. Contribution of Surface Distributions to Constant-Phase-Element (CPE) Behavior: 2. Capacitance. Electrochimica Acta. 2016;188:566573.

61. Torres VV, Rayol VA, Magalhães M, Viana GM, Aguiar LCS, Machado SP, et al. Study of thioureas derivatives synthesized from a green route as corrosion inhibitors for mild steel in $\mathrm{HCl}$ solution. Corrosion Science. 2014;79:108-118.

62. Senna LF, Luna AS. Experimental Design and Response Surface Analysis as Available Tools for Statistical Modelling and Optimization of Electrodeposition Processes. In: Sebayang D, Hasan SBH. Electroplating. Rijeka: InTech Open; 2012.

63. Presuel-Moreno FJ, Jakab MA, Scully JR. Inhibition of the Oxygen Reduction Reaction on Copper with Cobalt, Cerium, and Molybdate Ions. Journal of Electrochemical Society. 2005;152(9):B376-B387. 